\title{
Persamaan Gelombang Gravitasi untuk Teori Proca yang Digeneralisasi
}

\author{
Marliana $^{1}$, Agustina Widiyani ${ }^{1,2}$, Azwar Sutiono ${ }^{1}$, Agus Suroso ${ }^{1,3}$ and Freddy P. \\ $\operatorname{Zen}^{1,3}$
}

${ }^{1}$ Lab Fisika Teori, THEPI, Program Studi Fisika, Fakultas Matematika dan Ilmu Pengetahuan Alam, Institut Teknologi Bandung, Jl. Ganesha 10 Bandung 40132, Indonesia ${ }^{2}$ Program Studi Fisika, Fakultas Sains, Institut Teknologi Sumatera, Jl. Terusan Ryacudu, Jati Agung Lampung Selatan 35365, Indonesia

${ }^{3}$ Indonesia Center for Theoretical and Mathematical Physics (ICTMP), Faculty of Mathematics and Natural Sciences, Institut Teknologi Bandung, Jl. Ganesha 10 Bandung 40132, Indonesia

\section{E-mail: marliana.lutan@gmail.com}

\begin{abstract}
The direct detection of gravitational waves from binary black holes and neutron stars have been taking a new oportunities to test teori of gravity.The gravitational wave is affected by the modification of a gravity theory during propagation at cosmological distances. By comparing general equation of gravtiational wave and modification of gravity theory, is obtained equation of gravitational wave for the generalized Proca theories. As a result, we find equation of gravitational wave for the generalized Proca theory. We conclude that the massive vector field affected propagation of gravitational wave. we can use the result to test the generalized Proca theory.
\end{abstract}

Keywords: gravitaional wave, modification of a gravity theory, the generalized Proca theory

\begin{abstract}
Abstrak: Dengan terdeteksinya gelombang gravitasi secara langsung dari biner lubang hitam dan bintang neutron menjadi kesempatan untuk dapat menguji teori gravitasi yang sedang dikembangkan.Gelombang gravitasi secara umum dipengaruhi oleh modifikasi teori gravitasi selama penjalarannya pada jarak kosmologi. Dengan membandingkan persamaan gelombang gravitasi dengan teori modifikasi yang dikembangkan, diperoleh persamaan umum gelombang gravitasi dari teori gravitasi yang dikembangkan. Pada artikel ini diperoleh persamaan gelombang gravitasi untuk teori Proca yang digeneralisasi. Dapat disimpulkan bahwa fungsi yang mengandung vektor medan masif dapat mempengaruhi gelombang gravitasi. Persamaan ini dapat digunakan untuk menguji teori Proca yang digeneralisasi.
\end{abstract}

Kata kunci: gelombang gravitasi, modifikasi teori gravitasi, teori Proca yang digeneralisasi.

\section{PENDAHULUAN}

Telah diketahui bahwa alam semesta mengembang dengan percepatan tertentu. Sejak pertama kali dilakukan pengukuran percepatan alam semesta pada supernova type I maka diusulkan bahwa model materi gelap merupakan penjelasan terbaik untuk menggambarkan evolusi dinamis alam semesta. Karena dianggap keberadaan komponen yang tidak diketahui tersebut mencakup $95 \%$ dari total alam semesta. Permasalahannya, percepatan mengembangnya alam semesta ini belum diketahui secara pasti nilainya. Untuk menjawab permasalahan tersebut maka diusulkan dua cara yaitu dengan energi gelap dan modifikasi gravitasi. Teori modifikasi gravitasi merupakan pengembangan dari teori Einstein tentang relativitas umum. Berbagai model teori modifikasi gravitasi telah diusulkan, model awalnya adalah quitessence dan bentuk kinetik non linier dari medan skalar. Teori Hornsdeski merupakan bentuk paling umum dari teori modifikasi gravitasi ini, dengan kurvatur ruangwaktu dan medan skalar dimana persamaan geraknya sampai pada turunan kedua ruang waktu. Lalu diusulkan lagi bentuk medan yang menyebabkan munculnya energi gelap adalah medan 
Proca, maka dikembangkan teori Proca yang digeneralisasi. Teori ini dibangun dengan mempertimbangkan medan vektor massif dengan semua interaksi derivatif sehingga menghasilkan rambatan dua transversal dan satu longitudinal. Dalam perumusannya juga sudah memenuhi kondisi ketidakberadaan ghost dan ketidakstabilan perturbasi tensor, vektor, dan skalar.

Pada tahun 2015 dan tahun 2016 terdeteksi gelombang gravitasi dari lobang hitam oleh kolaborasi LIGO dan Virgo. Selanjutnya pada tahun 2017, terdeteksi lagi gelombang gravitasi dari bintang neutron. Hasil pengamatan ini merupakan bukti adanya gelombang gravitasi. Gelombang gravitasi ini dapat dihasilkan oleh benda masif yang mendapat gangguan. Hal ini mendukung teori relativitas umum yang diajukan oleh Einstein. Dalam relativitas umum, gelombang gravitasi merambat dengan kelajuan cahaya sampai dengan nilai tertentu bergantung pada formulasi umum dari teori modifikasi gravitasi yang digunakan. Dengan adanya data-data hasil pengamatan gelombang gravitasi ini, menjadi suatu jalan untuk menguji teori modifikasi gravitasi yang ingin dikembangkan. Dalam penelitian ini dilakukan untuk teori Proca yang digeneralisasi. Tahap awal yang dilakukan adalah dengan menentukan persamaan gelombang gravitasi teori Proca yang digeneralisasi. Pada penelitian ini mengacu ada metode yang dilakukan oleh Nishizawa untuk teori Horndeski.

\section{METODE PENELITIAN}

Metode yang digunakan dalam penelitian ini adalah studi pustaka dari berbagai literatur yang meliputi referensi dari berbagai jurnal internasional, buku-buku, maupun informasi dari berbagai media lain sebagai penunjang. Tahap-tahap penelitian meliputi: menentukan persamaan aksi untuk teori Proca yang digeneralisasi, menurunkan persamaan untuk mendapatkan tensor energi momentum untuk teori Proca yang digeneralisasi, mengubah bentuk persamaan tensor energi momentum teori Proca yang digeneralisasi ke bentuk persamaan gelombang gravitasi umum.

\subsection{Teori Proca yang Digeneralisasi}

Teori Proca yang digeneralisasi merupakan salah satu teori modifikasi gravitasi dengan mempertimbangkan medan vektor masif dengan interaksi turunan yang merambat hanya pada tiga polarisasi serta persamaan geraknya sampai pada orde ke dua dalam ruang waktu lengkung. Adapun lagrangian dan persamaan aksi untuk teori Proca yang digeneralisasi untuk empat dimensi sebagai berikut:

$$
\begin{aligned}
& S=\int d^{4} x \sqrt{-g}\left(\mathcal{L}+\mathcal{L}_{m}\right) \\
& \mathcal{L}=\mathcal{L}_{\mathrm{F}}+\sum_{i=2}^{5} \mathcal{L}_{i} \\
& \mathcal{L}_{\mathrm{F}}=-\frac{1}{4} F_{\mu \nu} F^{\mu \nu} \\
& \mathcal{L}_{2}=\mathrm{G}_{2}(\mathrm{X}) \\
& \mathcal{L}_{3}=\mathrm{G}_{3}(\mathrm{X}) \nabla_{\mu} A^{\mu} \\
& \mathcal{L}_{4}=\mathrm{G}_{4}(\mathrm{X}) \mathrm{R}+\mathrm{G}_{4 \mathrm{X}}(\mathrm{X})\left[\left(\nabla_{\mu} A^{\mu}\right)^{2}+c_{2} \nabla_{\rho} A_{\sigma} \nabla^{\rho} A^{\sigma}-\left(1+c_{2}\right) \nabla_{r} A_{\sigma} \nabla^{\sigma} A^{\rho}\right] \\
& \mathcal{L}_{5}=\mathrm{G}_{5}(\mathrm{X}) G_{\mu \nu} \nabla^{\mu} A^{v}-\frac{1}{6} G_{5 X}(X)\left[\left(\nabla_{\mu} A^{\mu}\right)^{3}-3 d_{2} \nabla_{\mu} A^{\mu} \nabla_{\rho} A_{\sigma} \nabla^{\rho} A^{\sigma}\right. \\
& \quad-3\left(1-d_{2}\right) \nabla_{\mu} A^{\mu} \nabla_{\rho} A_{\sigma} \nabla^{\sigma} A^{\rho}+\left(2-3 d_{2}\right) \nabla_{\rho} A_{\sigma} \nabla^{\gamma} A^{\rho} \nabla^{\sigma} A_{\gamma}
\end{aligned}
$$




$$
+3 d_{2} \nabla_{\rho} A_{\sigma} \nabla^{\gamma} A^{\rho} \nabla_{\gamma} A^{\sigma}
$$

Dengan $A^{\mu}$ adalah medan vektor dan $X=-\frac{1}{2} A_{\mu} A^{\mu}$, serta $F_{\mu v}=\nabla_{\mu} A_{v}-\nabla_{v} A_{\mu}$. Agar tetap homogen dan isotropi, maka medan vektor yang diberikan adalah

$$
A^{\mu}=(\phi(t), 0,0,0)
$$

2.2 Persamaan Gelombang Gravitasi Teori Proca yang Digeneralisasi

Bentuk umum persamaan Einstein untuk teori Proca yang digeneralisasi adalah

$$
G_{\mu \nu}+T_{\mu \nu}^{(A)}=\kappa^{2} T_{\mu \nu}^{(m)}
$$

Dengan $G_{\mu \nu}$ adalah tensor Einstein, $T_{\mu \nu}^{(A)}$ adalah tensor energi momentum dari teori Proca yang digeneralisasi, dan $\kappa^{2} T_{\mu \nu}^{(m)}$ adalah tensor energi momentum untuk materi. Sedangkan tensor Einstein itu adalah

$G_{\mu v}=R_{\mu \nu}-\frac{1}{2} R \eta_{\mu v}$

Gelombang gravitasi ditinjau dari teori modifikasi gravitasi, merupakan riak ruang waktu dari metrik ruang datar yang mendapat gangguan atau perturbasi, atau dinyatakan sebagai

$$
g_{\mu v}=\eta_{\mu v}+h_{\mu v}
$$

Dengan $\eta_{\mu v}$ merupakan metrik Minkowski dan $h_{\mu \nu}$ sebagai tensor perturbasi. Dimana $\left|h_{\mu \nu}\right| \square 1$ dimanapun dalam ruang waktu. Sedangkan tensor kurvatur Riemannnya adalah

$$
R_{\alpha \mu \beta \nu}=\frac{1}{2}\left(\partial_{\alpha} \partial_{\nu} h_{\mu \beta}+\partial_{\mu} \partial_{\beta} h_{\alpha \nu}-\partial_{\alpha} \partial_{\beta} h_{\mu \nu}-\partial_{\mu} \partial_{\nu} h_{\alpha \beta}\right)
$$

Dan tensor Riccinya

$$
R_{\mu \nu}=\frac{1}{2}\left(\partial_{\alpha} \partial_{\nu} h_{\mu}^{\alpha}+\partial_{\mu} \partial_{a} h_{v}^{\alpha}-\square h_{\mu \nu}-\partial_{\mu} \partial_{v} h\right)
$$

Tensor energi momentum untuk teori Proca diperoleh dengan memvariasikan persamaan aksi untuk teori Proca yang digeneralisasi terhadap metriknya, yaitu dengan

$$
T_{\mu \nu}^{(A)}=\frac{-2}{\sqrt{-g}} \frac{\delta S_{A}}{\delta g^{\mu \nu}}
$$

Formulasi umum untuk penjalaran gelombang gravitasi dinyatakan sebagai

$$
\ddot{h}_{i j}+(2+v) H \dot{h}_{i j}+\left(c_{T}^{2} k^{2}+a^{2} \mu^{2}\right) h_{i j}=a^{2} \Gamma_{\gamma i j}
$$

Dengan $h_{i j}$ adalah tensor pertubasi yang merupakan gelombang gravitasi dan tanda titik menyatakan turunan terhadap waktu konformal, $\mathrm{H}$ adalah parameter Hubble, a adalah percepatan mengembangnya alam semesta, $c_{T}$ adalah kelajuan gelombang gravitasi, $v$ merupakan laju perubahan massa Planck dan $\Gamma_{\gamma i j}$ menyatakan suku tambahan yang membangkitkan gelombang gravitasi. Agar kordinat gauge transformasi tetap dalam kondisi transversal, maka dibutuhkan gauge fungsi vektor $\chi_{\mu}$ yang menjadi fungsi kendala dengan kondisi $\square \chi_{\mu}=0$ sehingga dapat digunakan untuk menyederhakan tensor polarisasi dimana $\varepsilon_{\mu v}$ menjadi traceless, sehingga $\varepsilon_{\mu}^{\mu}=0$ begitu juga $\varepsilon_{\mu 0}=\varepsilon_{0 \mu}=0$. 


\section{HASIL DAN PEMBAHASAN}

Persamaan gelombang gravitasi untuk teori Proca yang digeneralisasi diperoleh dengan mengubah bentuk persamaan Einsten dari teori Proca yang digeneralisasi tersebut ke bentuk persamaan umum gelombang gravitasi dengan menggunakan persamaan (11) sampai dengan persamaan (16), untuk masing-masing suku diperoleh sebagai berikut

$$
\begin{aligned}
\ddot{h}_{i j}+(2+v) H \dot{h}_{i j}= & -\frac{1}{2} a^{2} \delta_{j k} \ddot{h} G_{4}(X)+\frac{1}{2} \ddot{h} G_{4}(X)+\ddot{h}_{i j} G_{4}(X)-\frac{1}{2} a^{2} \delta_{l m} h^{i j} \ddot{h}_{i j} G_{4}(X)-\frac{1}{2} h_{i j} \ddot{h} G_{4}(X) \\
& +\frac{1}{2} h^{i j} \ddot{h}_{i j} G_{4}(X)-\frac{1}{2} \phi^{2} \ddot{h}-\frac{3}{2} G_{5}(X) a^{2} H \phi \ddot{h}+G_{5}(X) a^{2} h_{m j} H \phi \ddot{h}+G_{5}(X) a^{6} H \phi \delta_{i j} \ddot{h} \\
& -G_{5}(X) \dot{\phi} \ddot{h}+G_{4}(X) \ddot{h}+G_{5}(X) \dot{\phi} \partial_{j} \dot{h}_{i}^{j}-G_{5}(X) \dot{\phi} \partial_{i} \dot{h}-3 G_{5}(X) a^{2} H \phi \partial_{j} \dot{h} \\
& +3 G_{5}(X) a^{2} H \phi \partial_{j} \dot{h}_{i}^{j}+2 \partial_{i} \dot{h} G_{4}(X)-2 \partial_{i} \dot{h}_{j}^{i} G_{4}(X)
\end{aligned}
$$

$$
\begin{aligned}
\left(c_{T}^{2} k^{2}+a^{2} \mu^{2}\right) h_{i j}= & G_{2}(X) h_{i j}+G_{3}(X) \dot{\phi} h_{i j}+3 G_{3}(X) H \phi h_{i j}+4 G_{3}(X) a^{2} \phi H h_{i j}+18 G_{4 X} \phi^{2} H^{2} h_{i j} \\
& -3 G_{5}(X) \dot{\phi} H^{2} h_{i j}-6 G_{5}(X) \phi H \dot{H} h_{i j}-9 G_{5}(X) \phi H^{3} h_{i j}-\frac{23}{6} G_{5 X} \phi^{3} H^{3} h_{i j} \\
& -\frac{19}{2} d_{2} G_{5 X} \phi^{3} H^{3} h_{i j}+\frac{1}{6} G_{5 X} \dot{\phi}^{3} h_{i j}+\frac{7}{2} G_{5 X} H \phi \dot{\phi}^{2} h_{i j}+\frac{7}{2} G_{5 X} \dot{\phi} \phi^{2} H^{2} h_{i j}
\end{aligned}
$$

$$
\begin{aligned}
a^{2} \Gamma_{\gamma i j}= & -a^{2} G_{2}(X) \delta_{i j}-3 G_{3}(X) a^{2} \phi H \delta_{i j}-2 G_{3}(X) a^{2} \phi H \delta_{i j}-10 G_{4 X} a^{2} \phi^{2} H^{2} \delta_{i j}+3 G_{5}(X) a^{2} \dot{\phi} H^{2} \delta_{i j} \\
& +9 G_{5}(X) a^{2} \phi H^{3} \delta_{i j}-6 G_{5}(X) a^{2} \phi H \dot{H} \delta_{i j}-18 G_{5}(X) a^{2} \phi H^{3} \delta_{i j}+\frac{1}{3} G_{5 X} a^{2} \dot{\phi}^{3} \delta_{i j}-\frac{1}{2} d_{2} G_{5 X} a^{2} \dot{\phi}^{3} \delta_{i j} \\
& +6 G_{5 X} a^{2} \phi^{3} H^{3} \delta_{i j}+\frac{53}{6} d_{2} G_{5 X} a^{2} \phi^{3} H^{3} \delta_{i j}-\frac{5}{2} G_{5 X} a^{2} \phi H \dot{\phi}^{2} \delta_{i j}-\frac{3}{2} G_{5 X} a^{2} \phi^{2} H^{2} \dot{\phi} \delta_{i j}
\end{aligned}
$$

Dari ketiga persamaan di atas, terlihat bahwa pada persamaan (18) yang mengandung nilai perubahan laju massa Planck, $v$, dipengaruhi oleh fungsi $\mathrm{G}_{4}$ dan $\mathrm{G}_{5}$ saja. Sedangkan kelajuan gelombang gravitasi, $c_{T}$, pada persamaan (19) dipengaruhi oleh semua fungsi $G_{2}, G_{3}, G_{4}$ dan $\mathrm{G}_{5}$ dan juga turunannya, artinya terjadinya interaksi dengan kurvatur atau ruang lengkung. Untuk suku tambahan yang membangkitkan gelombang gravitasi mengandung semua fungsi $\mathrm{G}_{2}, \mathrm{G}_{3}, \mathrm{G}_{5}$ dan turunan dari fungsi $\mathrm{G}_{4}$ dan $\mathrm{G}_{5}$.

\section{KESIMPULAN}

Dari hasil perhitungan persamaan gelombang gravitasi untuk teori Proca yang digeneralisasi ini dapat disimpulkan bahwa perubahan laju massa Planck yang dipengaruhi oleh fungsi $\mathrm{G}_{4}$ dan $\mathrm{G}_{5}$ saja, jika dilihat dari persamaan (6) dan (7) terlihat bahwa fungsi tersebut yang berinteraksi dengan kurvatur. Semua fungsi turut andil dalam membangkitkan gelombang gravitasi. Dimana setiap fungsi tersebut mengandung vektor medan masif Proca, artinya medan vektor masif ini menimbulkan gelombang gravitasi. 


\section{SARAN}

Dengan diperolehnya gelombang gravitasi teori Proca yang digeneralisasi, selanjutnya dapat diteruskan dengan menginterpretasikan hasil tersebut untuk memperoleh persamaan laju perubahan massa Planck dan kelajuan gelombang gravitasinya. Hasilnya lalu dapat dihubungan dengan data-data hasil pengamatan.

\section{DAFTAR PUSTAKA}

Abbott B.P et al, 2016, (LIGO Scientific Collaboration and Virgo Collaboration), Physical Review Letters 116.061102.

Abbott B.P et al, 2016, (LIGO Scientific Collaboration and Virgo Collaboration), Physical Review Letters 116.241103.

Abbott B.P et al, 2017, (LIGO Scientific Collaboration and Virgo Collaboration), Physical Review Letters 118.221101.

Abbott B.P et al, 2017, (LIGO Scientific Collaboration and Virgo Collaboration), Physical Review Letters 119.141101.

Abbott B.P et al, 2017, (LIGO Scientific Collaboration and Virgo Collaboration), Physical Review Letters 119.161101.

Abbott B.P et al, 2017, (Virgo, Fermi-GBM,INTEGRAL, LIGO Scientific), Astrophys. J.848, L13.

Heisenberg L, 2014, Journal od Cosmology and Astroparticle Physics, JCAP05(2014)015.

De Felice A. Et al, 2016, Journal od Cosmology and Astroparticle Physics, JCAP06(2016)048.

De Felice, A., L. Heisenberg, and S. Tsujikawa, 2017, Physical Review, D95, 123540(2017).

Lagos M et all, 2019, Physical Review D99, 083504(2019).

Saltas, I.D., et al, 2014, Physical Review Letters, PRL 113,191101(2014).

Nishizawa A, 2018, Physical Review, D97, 104037(2018).

Arai S, and A. Nishizawa, Physical Review, D97, 10438(2018).

Nunes, R.C., M.E.S. Alves, and J.C.N de Araujo, 2019, Physical Review D99, 0840022(2019).

Amendola L., et al, 2018, Journal od Cosmology and Astroparticle Physics, JCAP08(2018)030. 